\title{
Transport Accessibility at Regional Scale ${ }^{1}$
}

\author{
Oriol Biosca \\ MCRIT \\ Salvador Espriu 83, 08005 Barcelona, Spain \\ obiosca@mcrit.com
}

\section{Klaus Spiekermann}

Spiekermann \& Wegener, Urban and Regional Research (S\&W)

Lindemannstrasse 10

D-44137 Dortmund, Germany

ks@spiekermann-wegener.de

\section{Marcin Stępniak}

Institute of Geography and Spatial Organization, Polish Academy of Sciences

Twarda 51/55, 00-818 Warsaw, Poland

stepniak@twarda.pan.pl

\begin{abstract}
The main aim of the paper is to introduce a common methodology for case study accessibility analysis presented in the following chapters. Background information concerning the TRACC ESPON project is presented and a justification for the selection of case studies is provided. Finally, the generalised results of the in-depth analysis, conducted for particular case studies, are presented and compared.
\end{abstract}

Keywords: transport accessibility, accessibility indicators, Europe

\section{Introduction}

Accessibility is the main 'product' of a transport system. It determines the locational advantage of an area (i.e. a region, a city or a corridor) relative to all areas. Indicators of accessibility measure the benefits households and companies in an area derive from the existence and use of the transport infrastructure. The important role of transport infrastructure (i.e. networks and transport services) for spatial development in its most simplified form implies that areas with better access to the locations

1 This paper has been developed under the applied research project TRansport ACCessibility at regional/local scale and patterns in Europe led by Spiekermann \& Wegener Urban and Regional Research (S\&W) Germany. It has been financed by the ESPON 2013 Programme and its financial support is gratefully acknowledged. Texts, maps and conclusions stemming from research projects under the ESPON programme presented in this paper do not necessarily reflect the opinions of the ESPON Monitoring Committee. C ESPON, 2013. 
of input materials and markets will, ceteris paribus, be more productive, more competitive and hence more successful than more remote and isolated areas. Following this rationale, global and European accessibility are important location factors for companies and people who commute and travel for leisure. However, for the daily life of citizens, regional/local accessibility to jobs, services and public facilities is often more important than global or European accessibility.

To address the importance of accessibility to regional development at all territorial scales, the ESPON 2013 Programme, i.e. the European Observation Network for Territorial Development and Cohesion, launched a study on this topic. The ESPON project TRACC (TRansport ACCessibility at regional/local scale and patterns in Europe) aimed at collecting and updating the results of previous studies on accessibility at the European scale in order to extend the range of accessibility indicators by applying further indicators responding to new policy questions, to extend the spatial resolution of accessibility indicators and to explore the likely impact of policies at the European and national scale to improve global, European and regional accessibility in the light of new challenges, such as globalisation, energy scarcity and climate change.

This volume of EUROPE XXI provides a summary presentation of the accessibility analyses of TRACC aturban and regional scale. Under the project, this was achieved via seven case studies. Their main aim was to gain knowledge on accessibility patterns in different types of regions throughout Europe. Common methodology was implemented that allows to (a) test the proposed methodology for the particular type of accessibility and (b) to compare the results of individual case studies.

In the TRACC project, six different indicators were analysed for each case study, for private cars and public transport separately. This was supplemented by in-depth analysis of the potential impact of the implementation of all listed TEN-T investments (again, for private and public transport separately). The most significant and informative types of analyses were selected for this volume of EUROPE XXI. The selection combines the traditional accessibility indicators (access to regional centres, job accessibility and regional potential accessibility) as well as indicators that describe accessibility to services of general interest (access to health care facilities). Moreover, the analyses are based on public transport networks as well as on private transport (private cars). Finally, the analyses of the impact of the future TEN-T road network developments are also included in the chapters.

This introductory paper provides some more information on the common methodology and the selection of case studies, it also presents some basic results and conclusions. Each of the following chapters will present highly summarised results of the case studies in a comparable way.

\section{Common methodology for case study accessibility analysis}

One of the technical objectives of the regional case studies was to implement methodologies that would be as similar as possible in order to allow a comparison of the resulting accessibility patterns, not disturbed by problems induced by methodological differences. In each case study, a set of regional accessibility indicators as defined in the TRACC set of accessibility indicators was implemented, calculated and analysed in a highly comparable way.

Table 1 presents this common set of six accessibility indicators used for the case study analysis. There are two groups of accessibility indicators for travel. The first group follows the traditional set of accessibility indicators calculated at the European level. All indicators are calculated for municipalities, i.e. at the LAU2 level. However, in some case studies the calculation was performed for smaller raster cells first, then also aggregated to LAU2: 
- Access to regional centres. How distant or how far away is the nearest regional centre? Proximity to an urban centre has often been used as a proxy for accessibility to jobs and different services such as higher education, health care or commerce. The access to regional centre indicator is defined as minimum travel times by road and public transport to the nearest urban centre.

- Daily accessibility of jobs. How many jobs can be reached from the places of residence? This indicator deals with the opportunities on the regional labour market from the point of view of the population. The indicator is defined as the number of jobs reachable within a maximum commuting distance of 60 minutes by car and by public transport.

- Regional potential accessibility. What is the regional population potential of a municipality? The population potential is useful to evaluate different locations within a region from the viewpoint of economic actors, e.g. companies assessing the regional labour market, or retail industries assessing the market area. As for the other spatial levels, the population potential is defined as the sum of the population in destination areas weighted by the travel times necessary to get there. Modes considered are road and public transport.

Table 1. TRACC set of accessibility indicators for case study analysis

\begin{tabular}{|l|l|l|l|}
\hline \multirow{2}{*}{$\begin{array}{c}\text { Basic } \\
\text { characteristics }\end{array}$} & \multicolumn{1}{|c|}{ Travel cost } & \multicolumn{1}{c|}{$\begin{array}{c}\text { Cumulated } \\
\text { opportunities }\end{array}$} & \multicolumn{1}{c|}{ Potential } \\
\cline { 2 - 4 } $\begin{array}{l}\text { Travel } \\
\text { (traditional) }\end{array}$ & $\begin{array}{l}\text { Access to regional centres } \\
\text { Travel time to the nearest } \\
\text { regional centre by road and } \\
\text { public transport }\end{array}$ & $\begin{array}{l}\text { Daily accessibility } \\
\text { of jobs } \\
\text { Jobs accessible within } 60 \\
\text { minutes by road and public } \\
\text { transport }\end{array}$ & $\begin{array}{l}\text { Regional potential } \\
\text { accessibility } \\
\text { To population by road and } \\
\text { public transport }\end{array}$ \\
\hline $\begin{array}{l}\text { Travel } \\
\text { (to services } \\
\text { of general } \\
\text { interest) }\end{array}$ & $\begin{array}{l}\text { Access to } \\
\text { health care facilities } \\
\text { Travel time to the nearest } \\
\text { hospital by road and public } \\
\text { transport }\end{array}$ & $\begin{array}{l}\text { Availability of upper } \\
\text { secondary schools } \\
\text { Number of upper secondary } \\
\text { schools within } 30 \text { minutes' } \\
\text { travel time by road and } \\
\text { public transport }\end{array}$ & $\begin{array}{l}\text { Potential accessibility of } \\
\text { doctors by road and public } \\
\text { transport }\end{array}$ \\
\hline
\end{tabular}

The second group of indicators for regional case studies concerns destinations of specific relevance for daily life, namely services of general interest:

- Access to health care facilities. What is the travel time to the nearest hospital? Travel times for each municipality or raster cell by road and by public transport might show spatial diversity in access to this important health care facility.

- Availability of upper secondary schools. Are upper secondary schools that offer degrees which allow enrolment at a university available within reasonable travel time? Is there a freedom of choice between different options? The indicator is defined as the number of upper secondary schools that can be reached within 30 minutes.

- Potential accessibility of basic health care. What is the locational quality with respect to basic health care? Using access to doctors as destination activity in a potential accessibility indicator allows to assess the relative distribution of health care provision of different areas within the region covered by the case study. The indicator is defined as the total number of doctors located in the case study region weighted by travel times by road and public transport. 
The analysis of the current accessibility conditions for car travel and for public transport is followed by an analysis of how the planned trans-European transport networks would affect the regional accessibility pattern. For each region, the recent proposals of the European Commission for a TEN-T core network are implemented in the regional network databases. Local and regional accessibility impacts of TEN-T developments are demonstrated using the accessibility to population indicator. The potentials by car and by public transport are presented for the future situation, changes compared to the present are analysed in relative and absolute terms.

\section{Regions covered by case studies}

The TRACC project aimed at an exploratory analysis of regional accessibility patterns across Europe. To do so, three considerations have guided the selection of regional case studies:

- The case study areas for regional accessibility modelling in TRACC should cover a wide range of different types of regions in different parts of Europe. This asks either for a relative large number of case study regions or for relatively large case study areas that incorporate different types of regions.

- The comparison of regional/local accessibility patterns in different parts of Europe would be difficult if case study regions are limited to one or few NUTS-3 regions. These would be analysed in isolation if there is no information on regional accessibility in the surrounding regions. Therefore, case study areas should be larger in size.

- There are data constraints which are mainly related to network data. It is currently impossible to set up a harmonised network database for Europe, in particular for public transport, with the level of detail from which subsets could be extracted for regional case studies. Consequently, regional case studies have to be developed from existing regional network databases.

Based on these considerations, the TRACC project has developed a specific concept for the case study regions. Each regional case study in TRACC consists of two integrated spatial levels, the overall case study and a set of zoom-in areas.

- The regional case study area is usually defined at NUTS-0 or NUTS 1 level, i.e. contains a large number of NUTS-3 regions of different types.

- A number of zoom-in areas usually defined at NUTS-3 level should represent different types of regions within each case study region.

The regional accessibility models of the case studies were to be set up in a way that enables calculating accessibility indicators at least for LAU-2 regions, and for smaller raster cells if possible. This allows, on the one hand, to analyse the accessibility pattern for the wider area of the macroregion with different types of regions and, on the other hand, in-depth analyses for specific types of regions by examining zoom-in areas.

In order to implement this spatial concept for regional case studies, the case study selection process had to include a pragmatic component. Only areas for which project partners already had a database fairly suitable for accessibility modelling could be selected as case studies. Figure 1 shows the seven TRACC case study regions selected: West Mediterranean in Spain and France, Northern Italy, Bavaria in Germany, the Czech Republic, Poland, the Baltic States and Finland. Together, they form an arc stretching from the Mediterranean Sea in south-western Europe up to the far north of Nordic countries. 


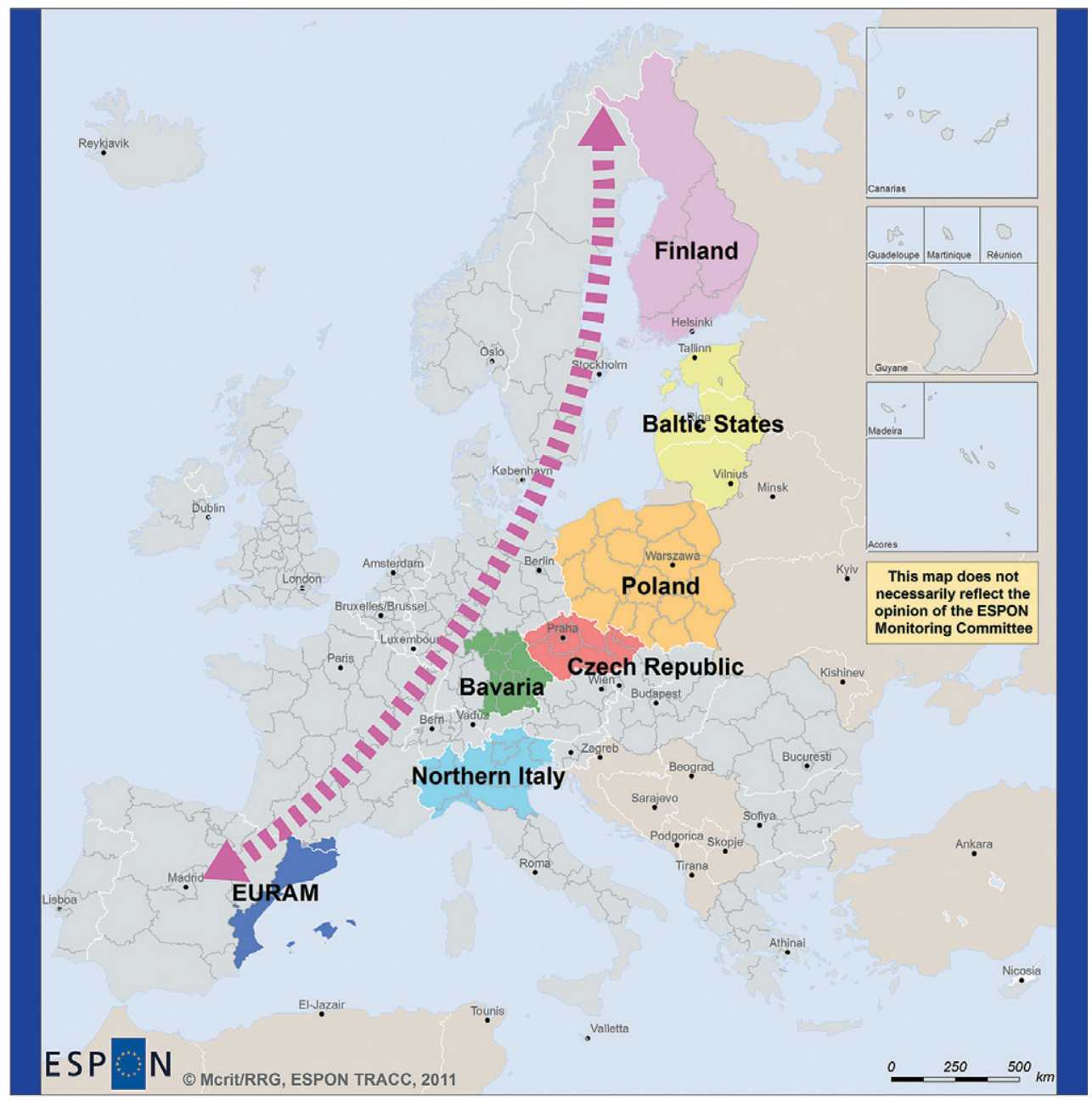

EUROPEAN UNION Part-financed by the European Regional Development Fund
INVESTING IN YOUR FUTURE

Figure 1. TRACC regional case studies.

The spatial sequence of case study regions across Europe is offering the possibility of additional contrasting of results along neighbouring case study regions. Transitions from one case study region to another were expected to be relatively smooth because of the role of common geographies and socio-cultural and historical linkages. Such cross-section of Europe would allow continuous analysis from the south to the north:

- The West Mediterranean region (EURAM) and seaside Northern Italy are coastal corridor regions fringed by mountainous back areas in the Mediterranean framework.

- Northern Italy and Bavaria are densely populated regions located in flatlands topped by major mountain ranges, in this case the Alps.

- Bavaria, the Czech Republic and Poland are part of the Central European plain, characterised by polycentric city structures. 
- Like many other new EU member states, the Czech Republic, Poland and the Baltic States face infrastructure deficits pending amendment.

- Poland, the Baltic States and Finland form the south-eastern fringe of the Baltic Sea region.

- The Baltic States and Finland are peripheral regions with low density figures, conditioned by rigorous climates.

The case study areas cover a wide range of different types of regions in different parts of Europe. They cover both core and peripheral areas, inland, coastal and insular territories, urban and rural territories, densely and sparsely populated areas, flat and mountainous territories, territories located both in the old EU-15 countries and in the new EU Member States. Contrasting the case study regions with nine standard ESPON territorial typologies, urban-rural, metropolitan regions, border regions, island regions, sparsely populated regions, outermost regions, mountainous regions, coastal regions, regions and regions in industrial transition yields that the 275 NUTS-3 regions of the case study areas have almost the same share of regions of each type of region as the whole ESPON space for each regional typology.

\section{Summary results of accessibility to regional and local destinations}

Access time to the nearest regional centre

In all case studies, the results are relatively similar for car with minimum values ( $25^{\text {th }}$ percentile) - around 20 to 30 minutes, and maximum values ( $75^{\text {th }}$ percentile) - around 40 to 60 minutes (Figure 2). More populated case studies tend to yield better values (Poland, Northern Italy, Western Mediterranean), while case studies comprising sparsely populated regions tend to provide higher access times (Finland, Baltic States, the Czech Republic). Access time to the nearest regional centre by public transport provides much greater diversity of results. While minimum values ( $25^{\text {th }}$ percentile) are fairly similar for all regions - around 30 to 40 minutes (except in the Baltic States, with 60 minutes), maximum values ( $75^{\text {th }}$ percentile) show a wider dispersion from around 60 minutes for Northern Italy case study to 120 minutes for the Baltic States (Figure 2.)

\section{Access time to hospitals}

Minimum access times ( $25^{\text {th }}$ percentile) and maximum access times $\left(75^{\text {th }}\right.$ percentile) are lower than those for accessing regional centres in all case studies (Figures 3 and 4). This reflects the fact that the provision of hospitals in most European countries is generally also the case in cities below 50,000 inhabitants. Therefore, the health care system can be accessed more easily than the network of medium-sized cities. The relative differences of access times between urban, intermediate and rural regions are similar to those for regional centres. 


\section{Finland}



\section{Poland}

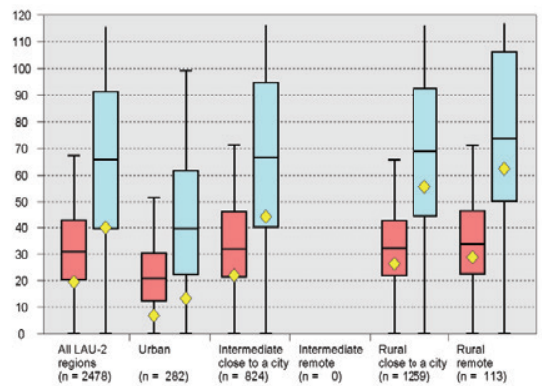

\section{Bavaria}

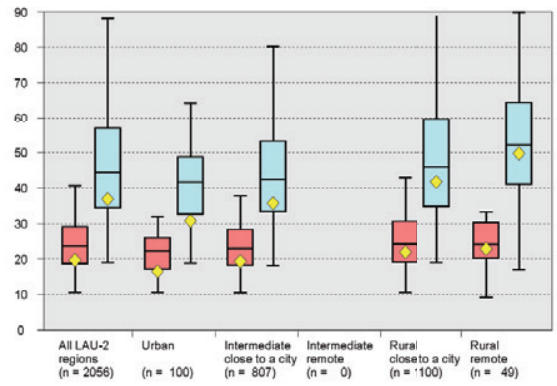

\section{West Mediterranean}

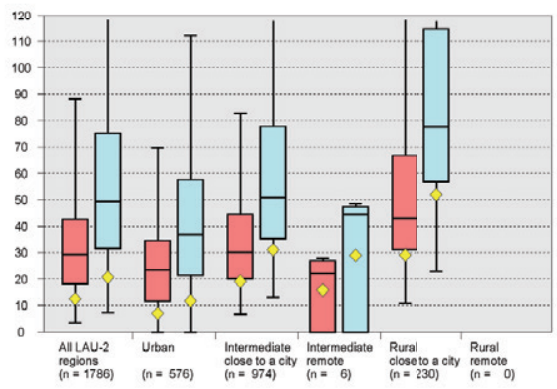

\section{Baltic States}

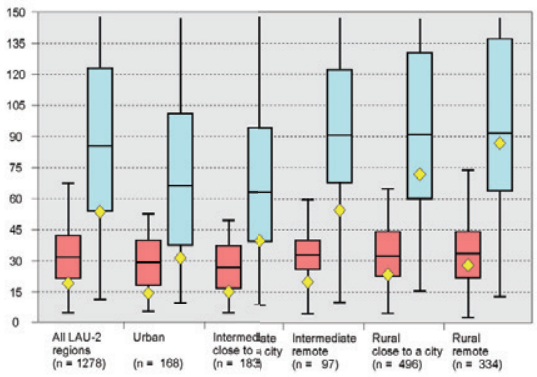

\section{Czech Republic}



\section{Northern Italy}

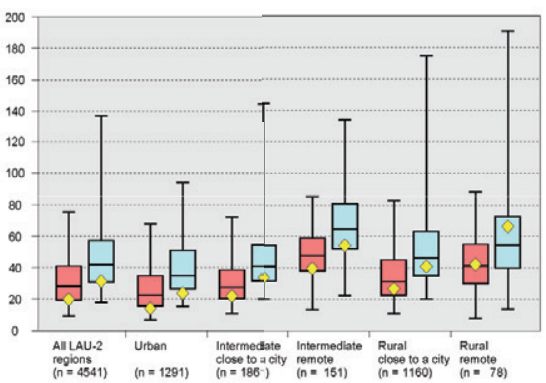

Figure 2. Travel time to the nearest regional centre by urban-rural typology (minutes). 


\section{Travel time to nearest hospital} by car (LAU-2, 2012)

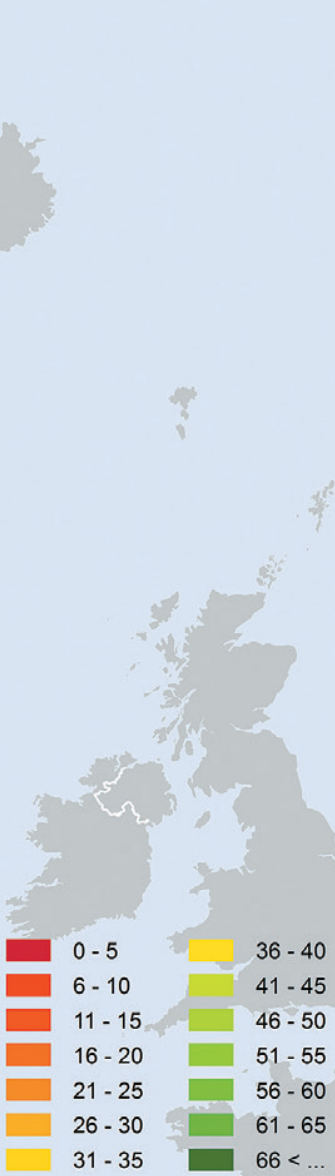

Source:

Accessibility models of TRACC TPG: FOGIS, IGIPZ PAN, MCRIT, PrF UK, RRG, S\&W, TRT

(C) EuroGeographics Association for administrative boundaries



Figure 3. Travel time to nearest hospital by car. 


\section{Travel time to nearest hospital by public transport (LAU-2, 2012)}

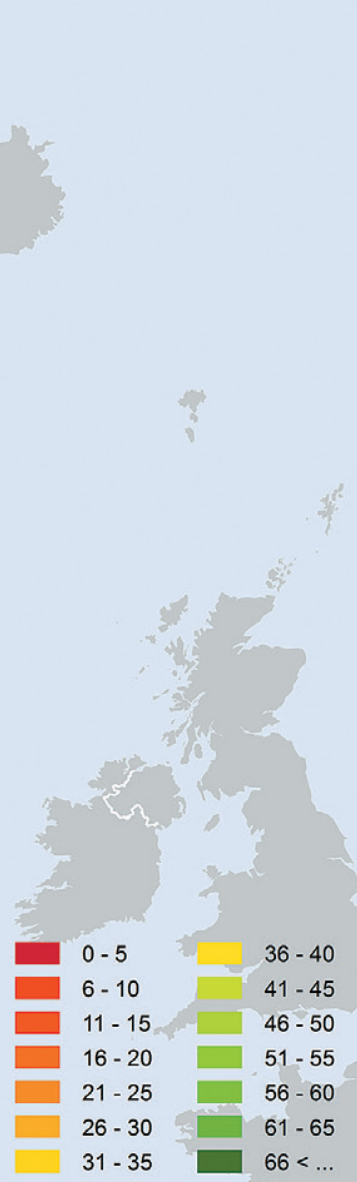

Source:

Accessibility models of TRACC TPG: FOGIS, IGIPZ PAN, MCRIT, PrF UK RRG, S\&W, TRT

(C) EuroGeographics Association for administrative boundaries

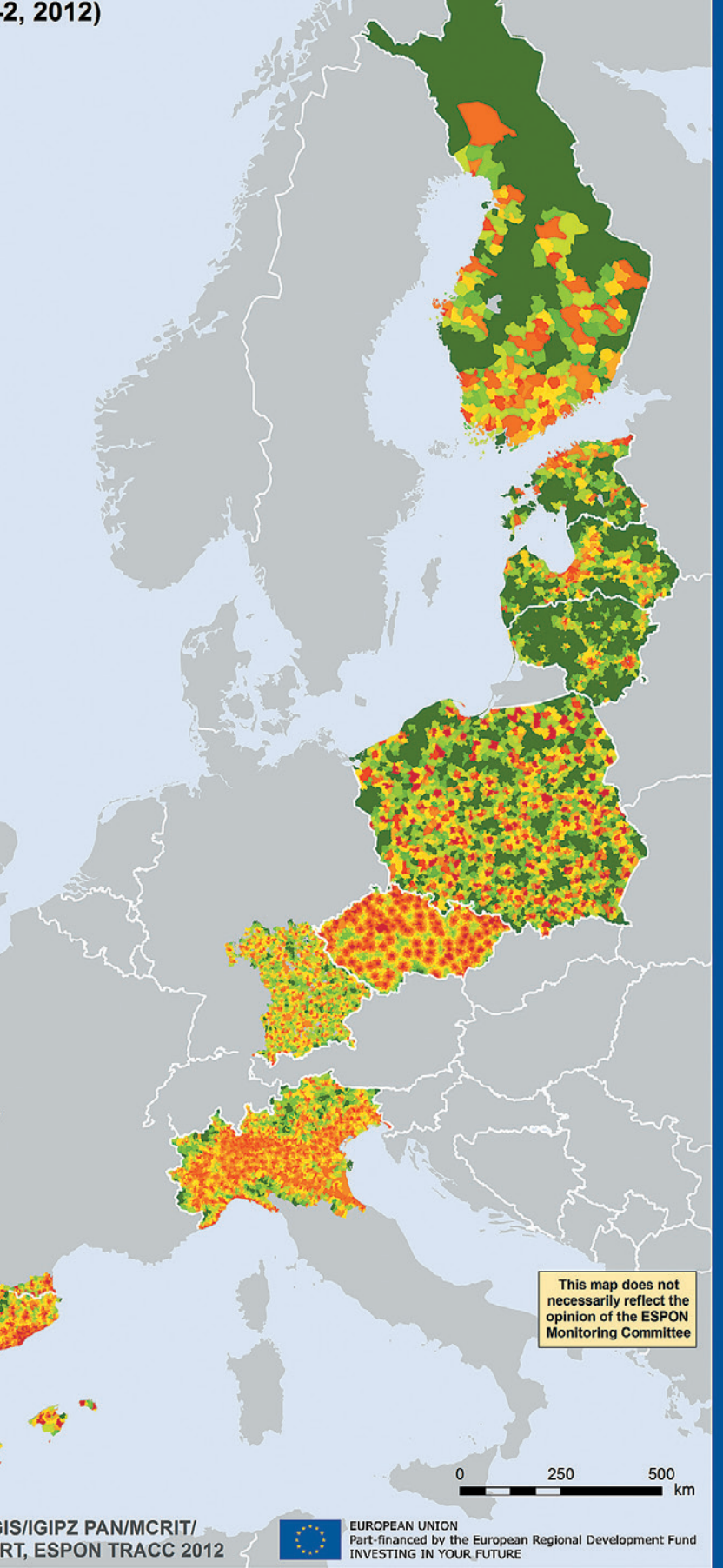


INVESTING IN YOUR FUTURE

Figure 4. Travel time to nearest hospital by public transport. 
Availability of jobs and secondary schools

In all case studies, these indicators reveal a more unbalanced performance between different territorial typologies than all other indicators. In all cases, except for the Czech Republic, urban regions have a clearly different performance in relation to intermediate and rural regions in terms of reaching opportunities. This is especially important for those travelling by car, but also relevant for those using public transport. The overall magnitude of cumulated opportunities varies widely from one case study to another, mostly depending on the population size.

\section{Potential accessibility to the population and to medical practitioners}

The potential type indicators show a much more unbalanced pattern between urban and rural regions than access time indicators (Figures 5 and 6). As expected, all urban regions perform substantially better than intermediate and rural regions, and much better than overall case study averages. Differences between different territorial typologies are more visible in the case of accessibility by car than by public transport.

\section{Conclusions}

Minimum availability of functions vs. diversity of services and opportunity supply

Indicators considering solely the availability of activities and services, i.e. travel time to the closest target activity or service, provide more balanced patterns relating to the territory than indicators accounting for the magnitude of available supply; regardless if they consider cumulated opportunities or total potential accessibility. The latter tend to reflect the polarisation between large metropolises and well-connected transport corridors, and quickly diminish towards more remote areas, while the former tend to provide more balanced patterns across territories. This shows that in most areas in Europe minimum service and administrative endowments are granted to a reasonable extent (e.g. at least one hospital available, at least one regional centre available), but differences are discovered to be more acute when analysing the number of possible alternatives for choice between the most populated urban areas and more sparsely populated rural areas (e.g. number of available jobs, schools, doctors).

\section{Public service endowment $v$ s availability of economic/social activities and private services}

In general, it seems that the distribution of public services in Europe is much more balanced than the distribution of economic and social activity (population, jobs). This can be attributed to the nature of European welfare systems, where administrations care for minimum endowment of services in less accessible areas, e.g. in rural or peripheral areas. A few case studies, however, have pointed out the danger of reducing accessibility to public services driven by the financial crisis in Europe, due mostly to the withdrawal of the public sector and the process of recentralisation of services towards larger regional centres. 


\section{Potential accessibility to population by car (LAU-2, 2012)}

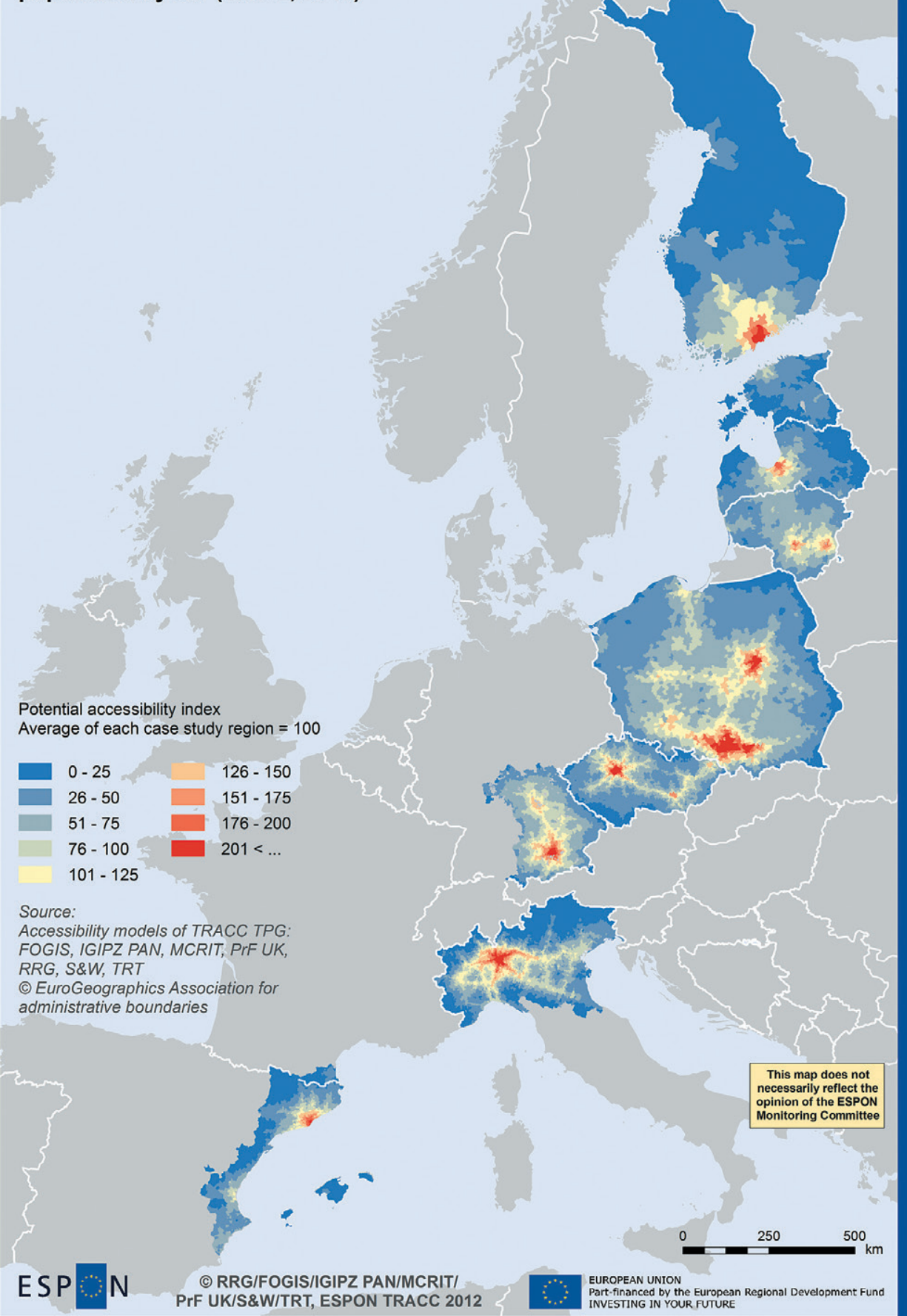

Figure 5. Potential accessibility to population by car (index: each case study average $=100$ ). 


\section{Potential accessibility to population} by public transport (LAU-2, 2012)

Potential accessibility index Average of each case study region $=100$
$0-25$ $126-150$
$26-50$
$151-175$
$51-75$
$176-200$
$76-100$ $201<\ldots$
$101-125$

Source:

Accessibility models of TRACC TPG: FOGIS, IGIPZ PAN, MCRIT, PrF UK, RRG, S\&W, TRT

(C) EuroGeographics Association for administrative boundaries

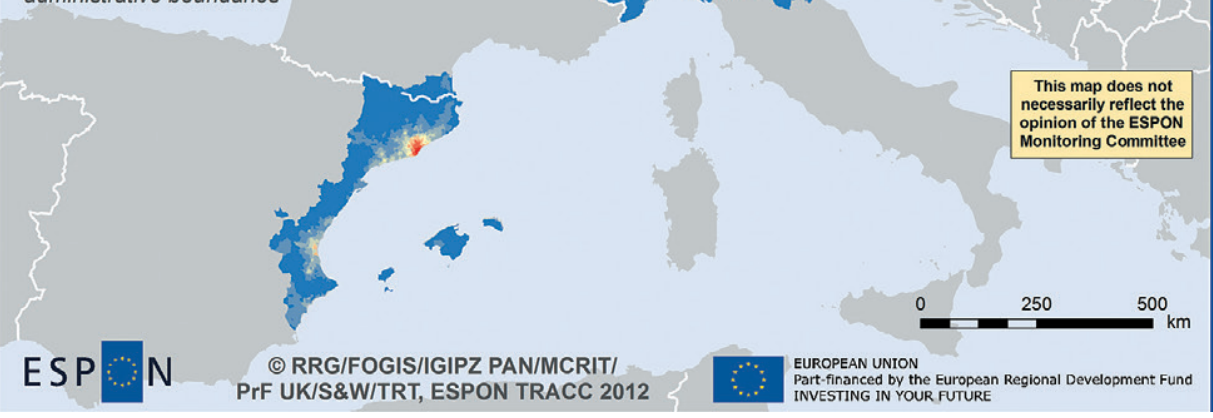

Figure 6. Potential accessibility to population by public transport (index: each case study average $=100$ ). 
Public transport accessibility vs car accessibility

The results of the seven case studies illustrate that an analytical distinction between different modes is clearly needed. Accessibility patterns for cars and public transport differ to a large degree with respect to the level of accessibility, and also with the spatial pattern. While accessibility for cars tends to form some sort of plateaus of good accessibility, the same indicator for public transport form 'stretches' and 'bands' of high accessibility along certain transport axis, interrupted by areas of low accessibility where public transport is almost or completely missing. Accessibility levels by car are in general much higher than those for public transport. However, in core cities of urban agglomerations and along some well-served axes public transport is able to reach as high accessibility levels as cars do.

\section{Absence of services vs. absence of infrastructure}

Accessibility is a matter of two components, i.e. transport infrastructure endowment and availability of services. In some case studies, low accessibility values tend to pertain to the most remote areas within the regions, often substantially less populated (e.g. in interior regions of the Western Mediterranean case study or in northern regions of the Finland case study). In other case studies, low accessibilities are mostly driven by poor transport infrastructure endowment, more often in Eastern than in Western Europe (e.g. in Poland, the Baltic States and the Czech Republic). In this respect, the reports on Economic and Social Cohesion by DG Regio $(2007,2010)$ point out that improved accessibility tends to create new job opportunities for rural and urban areas, but that potentials from improving accessibility depend on the previous competitiveness of the regions concerned, i.e. some regions liable to lose out as they become more open to competition from elsewhere. The reports emphasise the importance of combining investment in transport infrastructure with support for businesses and human capital development to achieve sustainable economic and social development.

\section{European periphery vs. European core}

In general, no significant differences in terms of regional and local accessibility can be observed between case studies covering the European periphery (e.g. Finland, Baltic States or West Mediterranean) and case studies covering the European core. Regional and local accessibility in all the case studies depends on the total level of population living in the concerned region and the level and quality of transport infrastructure endowment to a higher extent.

\section{Accessibility indicators}

The accessibility of a region cannot be assessed using one indicator alone. In all case studies of the ESPON TRACC project, a set of six different accessibility indicators was implemented, which should help analysing different aspects of access to markets and to public services. In fact, the results for the different indicators show that this broad set is quite useful as individual indicators depict different facets and different spatial structures. 
http://rcin.org.pl 